\title{
Contextual determination of apparent weight as demonstrated by the method of constant stimuli
}

\author{
DOROTHY DINNERSTEIN, FRANK CURCIO AND JACK CHINSKY 1
}

RUTGERS UNIVERSITY

The contextual determination of apparent weight is here confirmed with a constant-stimuli procedure. S, judging weights lifted in his right hand, makes a short set of suciessive comparisons between a standard (s) and a series of variable (v) weights. Simultaneously, he lifts his left hand non-judged context-weights (cws) which provide differing backgrounds for $s$ and $v$ respectively. The cws prove to exert consistent effects on the apparent heavinesses of the judged weights, as reflected in the frequency with which every $v$ in the series is judged lighter vs heavier than s.

In view of what is known about other modalities, it seems reasonable to expect that the general principle of contextual determination of local phenomenal intensities should hold also for weight perception. Helson's $(1947,1948)$ classic demonstrations that this is the case rested, however, on single-stimuli data, which were open to the objection (Stevens, 1958) that they could be reflecting context-induced shifts, not in "sensory excitability," but merely in the verbal category chosen by $\mathrm{S}$ from a limited rating-scale to characterize an otherwise unchanged item occupying a new relative position in a changed stimulus array. ${ }^{2}$

Here, in support of the view that context affects S's actual experience of heaviness, not just the name he gives to the experience, the method of constant stimuli is employed as follows: $\mathrm{S}$, using his right hand, makes a classic set of paired comparisons between a standard (s) and a series of variable (v) weights. But $s$ and $v$ appear against differing backgrounds, for along with each member of the comparison pair, $\mathrm{S}$ lifts in his left hand one of two contrasting non-judged context-weights (cws); s's cw is light and v's cs heavy, or vice versa. To the extent that these differing cw's deflect the apparent weights of their companions in opposite directions, they should affect the probability that $\mathrm{v}$ will be judged heavier (lighter) than s.

Method

Ss, Rutgers University undergraduates, were tested individually. Weights (plastic pillboxes of 1-in. diameter filled with lead shot and absorbent cotton or mercury) stood on two revolving trays, so arranged that they could be moved quickly into S's grasp. S, blindfolded, sat resting his elbows on a table. With wrist-motions, at signals from $\mathrm{E}$, he lifted, and $2 \mathrm{sec}$. later replaced, $\mathrm{s}$ in the right hand and a context weight (cw) in the left. After $3 \mathrm{sec}$. he similarly lifted and replaced $v$ in the right hand and a $\mathrm{cw}$ in the left. His task was described to him beforehand as follows: "Please tell us if the second object in your right hand is heavier or lighter than the first object in your right hand. Remember, you will be lifting objects with your left hand but will not be judging them. You will only be comparing the weights that you lift with your right hand. In other words, if the second object that you lifted with your right hand is heavier than the first object that you lifted with your right hand you will say 'heavier.' If the second object that you lifted with your right hand is lighter than the first object that you lifted with your right hand you will say 'lighter.' "

"Equal" or "don't know" judgments were not allowed, $S$ being instructed to respond "guess heavier" or "guess lighter" if uncertain. After a 6-8 sec. interval, during which $\mathrm{S}$ stated his judgment, the next two weight-pairs were similarly presented.

Under all conditions, $\mathrm{s}$ weighed $80 \mathrm{gm}$; the seven $\mathrm{v}$ weights, $65,70,75,80,85,90$, and 95 gm respectively, were arranged in a different random order for each block of seven judgments. Each $\mathrm{S}$ made two blocks of judgments-i.e., two comparisons per $\mathrm{v}$ weight-for each experimental condition.

In one condition, $s$ was always accompanied by a 320 $\mathrm{gm} \mathrm{cw}$ and $\mathrm{v}$ by a $20-\mathrm{gm} \mathrm{cw}$; in another condition, vice versa. Thirty Ss made judgments under both these conditions, 15 in the above order and 15 in the opposite order. In a control condition (identical with the one just described, except that S's left hand was idle and the instructions appropriately modified), another group of 30 Ss made judgments without cws. All Ss were righthanded.

Results

Comparison of the dotted with the solid lines of Fig. 1 makes clear a fact of some technical importance for further work: without cws the heavier $\mathrm{v}$ weights were more often correctly judged heavier than $s$, and the lighter $\mathrm{v}$ weights more often correctly judged lighter than $s$, than in either of the two conditions with cws. The presence per se of the light and heavy cw's appears, then, to reduce over-all reliability, or accuracy, of judgment.

This being so, the crucial comparison for present purposes lies between the two experimental conditions: as the two solid lines of Fig. 1 show, the perceived weight of $\mathrm{v}$ relative to s shifts consistently when their respective cws are interchanged: note that with the light $\mathrm{cw}$ accompanying $\mathrm{v}$ and the heavy $\mathrm{cw}$ accompanying $\mathrm{s}$, (line A) every one of the seven $v$ weights was judged heavier than $\mathrm{s}$ more often than in the opposite situation (line C).

\section{Discussion}

These findings seem to leave no doubt about the general point that perceived heaviness is affected by 


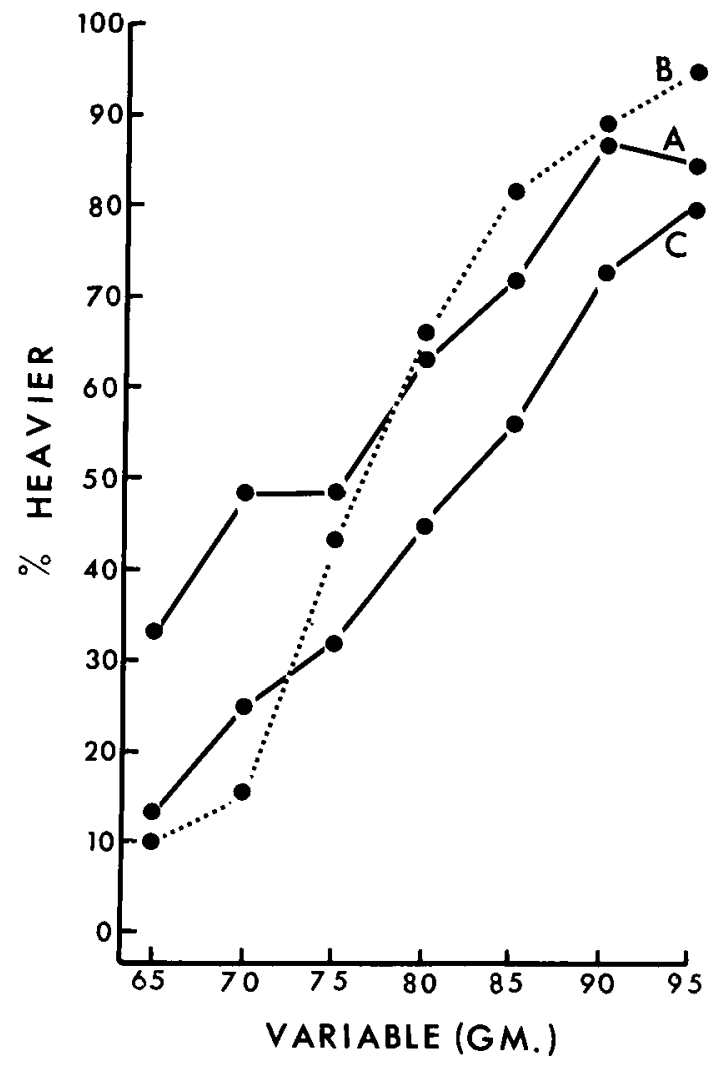

Fig. 1. Successive Intramanual Weight Comparisons as Affected by Simultaneous Intermanual Context Weights. ( $N$ of Ss per condition $=30$. $N$ of judgments per $v$-weight per condition $=60$. Line $A$ : 320-gm cw accompanies $S, 20-\mathrm{gm} \mathrm{cw}$ accompanies $v$. Line $B$ : no cws. Line C: 20 -gm $\mathrm{cw}$ accompanies $s, 320-\mathrm{gm} \mathrm{cw}$ accompanies $\mathrm{v}$.)

context. A number of more specific questions require further exploration.

Fig. 1, for example, reflects the joint effect of both heavy and light cws. Pilot experiments indicate that each of these cws, employed without the other, exerts nearly as large an effect in the expected direction as the two together. This confirms that both are effective and at the same time makes it clear that their joint effect is by no means equal to the sum of their separate influences. Further experiments are in progress to clarify this question. A second necessary line of inquiry is to explore systematically how a cw's influence varies with the weight-difference between itself and its accompanying judged weight: there is no reason to assume that the present weight-relationships, arrived at informally, reveal the optimal possible size of such an influence. Third, experiments involving more trials per $S$ are required to explore the temporal course of this phenomenon with repeated exposure to the cws.

The present experiment, then, is here reported (a) to confirm that contextual influence on judged heaviness exists as a genuine perceptual fact, not a purely semantic one depending on category ratings (Stevens, 1958); (b) to extend the observation that weights lifted in one hand affect judgments of weights lifted in the other (Dinnerstein, 1965); and (c) to introduce a technique by which the technical advantages of the method of constant stimuli can be brought to bear on further study of weight context phenomena.

\section{References}

Dinnerstein, D. Intermanual effects of anchors on zones of maximal sensitivity in weight discrimination. Amer. J. Psychol., 1965, $78,66^{-74}$.

Harvey, D. A., \& Campbell, D. T. Judgments of weight as affected by adaptation range, adaptation duration, magnitude of unlabelled anchor, and judgmental language. J. exp. Psychol., 1963, $63,12-21$.

Helson, H. Adaptation level as a frame of reference for prediction of psychophysical data. Amer. J. Psychol., 1947, 60, 1-29.

Helson, H. Adaptation level as a basis for a quantitative theory of frames of reference. Psychol. Rev., 1948, 55, 297-313.

Stevens, S. S. Adaptation level vs. the relativity of judgment. Amer. J. Psychol., 1958, 71, 633-646.

\section{Notes}

1. The second and third authors are now at Clark University and the University of Rochester respectively. Some of the data reported here were collected by George Michel and Isa Gerstein with partial support from the Research Council of Rutgers University.

2. Harvey \& Campbell (1963) approached this difficulty by comparing single-stimuli category ratings with absolute estimates in terms of ounces, and found that the latter measure yields a smaller, but nevertheless substantial, context effect; thus purely semantic factors, while probably contributing to the effect usually obtained with the method of single stimuli, seem by no means wholly to account for it. In a first attempt to bring the advantages of the method of constant stimuli to bear on this problem, Dinnerstein (1965) showed that the weight (light vs heavy) of a steady nonjudged "anchor," lifted repeatedly in the left hand while s makes successive comparisons between $s$ and $v$ in the right hand, affects the locus of maximally accurate discrimination within the $\mathrm{v}$ series, confirming Helson's (1948) contention that the location of the range of currently-attended-to stimuli determines the location of the zone within which S's discriminations are most sensitive. The present study, employing a new, more direct technique, addresses itself to intermanual context effects, not merely on discriminative sensitivity, but on phenomenal heaviness itself. 